\title{
Endophytic bacteria associated with endangered plant Ferula sinkiangensis K. M. Shen in an arid land: diversity and plant growth-promoting traits
}

\author{
LIU Yonghong ${ }^{1,2}$, GUO Jianwei ${ }^{1,3}$, LI Li $^{1}$, Mipeshwaree D ASEM ${ }^{4}$, ZHANG Yongguang ${ }^{1}$, \\ Osama A MOHAMAD ${ }^{1,5}$, Nimaichand SALAM ${ }^{4}$, LI Wenjun ${ }^{1,4^{*}}$ \\ ${ }^{1}$ Key Laboratory of Biogeography and Bioresource in Arid Land, Xinjiang Institute of Ecology and Geography, Chinese \\ Academy of Sciences, Urumqi 830011, China; \\ ${ }^{2}$ University of Chinese Academy of Sciences, Beijing 100049, China; \\ ${ }^{3}$ Key Laboratory of Crops with High Quality and Efficient Cultivation and Security Control, Yunnan Higher Education \\ Institutions, Honghe University, Mengzi 661100, China; \\ ${ }^{4}$ State Key Laboratory of Biocontrol and Guangdong Provincial Key Laboratory of Plant Resources, School of Life Sciences, \\ Sun Yat-Sen University, Guangzhou 510275, China; \\ ${ }^{5}$ Environmental Science Department, Institute for Post Graduate of Environment Study, Arish University, Arish 45511, Egypt
}

\begin{abstract}
Ferula spp. are traditional medicinal plants found in arid land. Large-scale excavation for extracting bioactive compounds from the plants in arid regions of Xinjiang over the last few years has, however, significantly decreased their distributions. Due to the urgent need for preservation of these plant resources, along with the need of searching for alternative source of the useful metabolites, it is important to screen the endophytic microbial resources associated with the plant Ferula sinkiangensis K. M. Shen. In the study, a total of 125 endophytic bacteria belonging to 3 phyla, 13 orders, 23 families, and 29 genera were isolated based on 16S rRNA gene sequencing data. Among the different isolates, three strains isolated from roots were potential novel species of the genera Porphyrobacter, Paracoccus and Amycolatopsis. In this study, $79.4 \%$ and $57.1 \%$ of the total isolates were capable of producing indole-3-acetic acid (IAA) and siderophore, respectively. And, $40.6 \%$ of the strains inhibit the growth of fungal pathogen Alternaria alternata, $17.2 \%$ and $20.2 \%$ strains were positive for antagonism against Verticillium dablia 991 and $V$. dablia 7 , respectively. These results demonstrated that $F$. sinkiangensis is a rich reservoir of endophytic bacterial resources with potential for production of biologically important functions such as plant growth-promoting factors.
\end{abstract}

Keywords: endophytic bacteria; Ferula sinkiangensis; endangered species; growth promoting

Citation: LIU Yonghong, GUO Jianwei, LI Li, Mipeshwaree D ASEM, ZHANG Yongguang, Osama A MOHAMAD, Nimaichand SALAM, LI Wenjun. 2017. Endophytic bacteria associated with endangered plant Ferula sinkiangensis K. M. Shen in an arid land: diversity and plant growth-promoting traits. Journal of Arid Land, 9(3): 432-445. doi: $10.1007 / \mathrm{s} 40333-017-0015-5$

\section{Introduction}

An endophyte, or more particularly endophytic bacteria, is an endosymbiont that lives within a plant for at least a part of its life cycle without causing apparent disease (Hallmann et al., 1998). It has been demonstrated that many endophytes are advantageous to host plants in a mechanism similar to most plant growth-promoting rhizobacteria by either providing plant growth promoting (PGP) factors or protecting against insect, pest or plant pathogens (Feng et al., 2006; Vurukonda et al., 2016; Wang et al., 2016). The major PGP factors produced by endophytic bacteria include

${ }^{*}$ Corresponding author: LI Wenjun (E-mail: liwenjun3@mail.sysu.edu.cn)

Received 2016-10-15; revised 2017-02-17; accepted 2017-04-12

(C) Xinjiang Institute of Ecology and Geography, Chinese Academy of Sciences, Science Press and Springer-Verlag Berlin Heidelberg 2017

http://jal.xjegi.com; www.springer.com/40333 
phytohormones such as auxins and indole-3-acetic acid (IAA), enzymes involved in growth regulation and siderophore (Boukhalfa and Crumbliss, 2002). They can also enhance plant growth by fixing atmospheric nitrogen and/or solubilizing insoluble inorganic phosphates (Triplett, 1996; Wang et al., 2009). In fact, biological nitrogen fixation and phosphate solubilization processes are considered an important PGP mechanism as these processes convert the abundantly available, unutilizable atmospheric nitrogen and phosphorus into accessible forms (Meunchang et al., 2006; Nimaichand et al., 2016). The study of endophytic bacteria and its interaction with the host is an important means to understand their ecological functions and explore their potentials for biotechnological applications, e.g., preparation of eco-friendly agricultural bioinoculants (Weller, 1988; Emmert and Handelsman, 1999; Bloemberg and Lugtenberg, 2001).

Endophytic bacteria ubiquitously inhabit most of the plant species and have been isolated from a variety of plants (Lodewyck et al., 2002). However, with relation to plants in extreme environments, limited studies have been done to explore the world of endophytic bacteria (Liu et al., 2016). Xinjiang of China is a typical arid environment where twenty-six varieties of Ferula spp., halophytic plants with medicinal properties, are found (Pimenov and Leonov, 2004). Despite the rich diversity of Ferula spp., Ferula sinkiangensis K. M. Shen is in threat of extinction due to overutilization and other man-made destruction. Since endophytes adapted to the extremely arid environment are most likely to possess special functions (Qin et al., 2009; He et al., 2015), it is important to explore its biological natures.

Current understanding on endophytic bacteria and their community structure on plant tissues is a result of culture-based microbial diversity analysis. But majority of the naturally occurring bacteria fail to be cultured, therefore limiting our knowledge on the functional aspect of the total bacterial community. On the other hand, culture-independent studies of microbial community provide less bias information on bacterial community structure and their functional roles in the ecology. Despite the limitation of culture-based approaches, it has an advantage over the culture-independent method in that pure cultures can be utilized for biotechnological applications. The present study involved the isolation of endophytes from different tissues of $F$. sinkiangensis and analyzed the distribution pattern among the plant tissues. In addition, the plant growth promoting traits and their bio-control potential were studied.

\section{Materials and methods}

\subsection{Study area and sampling}

Six plant samples of F. sinkiangensis were collected from three sites in Shihezi, Xinjiang $\left(44^{\circ} 08^{\prime} \mathrm{N}, 86^{\circ} 52^{\prime} \mathrm{E}\right.$; $836 \mathrm{~m}$ a.s.1.) on 15 August 2015 . These three sites were separated by a distance of at least $500 \mathrm{~m}$ from each other. The samples were rinsed thoroughly in running tap water within $24 \mathrm{~h}$ to exclude samples with symptoms of disease or superficial damage. After proper washing, the plant samples were separated into stems and roots (Ferula sp. is perennial, monocarpic and ephemeroid plants, only stems and roots are remained during the sampling period because of dormancy).

\subsection{Surface sterilization and isolation of endophytic bacteria}

A 3-step surface sterilization procedure (1-min wash in 75\% ethanol, 8 -min wash in 5\% $\mathrm{NaOCl}$ and subsequent rinsing in sterile distilled water for five times) was adopted for each tissue (Liu et al., 2016). To check the effectiveness of the surface-sterilization, we plated the distilled water of the final rinse onto yeast extract-malt extract agar (ISP 2, $\mathrm{pH} 7.2$ ) plate and incubated at $30^{\circ} \mathrm{C}$. The sterilization was considered complete if no microbial growth was observed on the medium.

Sterilized samples were air dried for 2 days at room temperature and were aseptically homogenized by sterilized commercial blender (Joyoung, JYL-C012). The homogenized tissue was diluted with sterile water to give a final concentration of $10^{-2}-10^{-4}$, followed by plating 40 $\mu \mathrm{L}$ of the tissue suspension onto the media M1 to M8 and M10 as defined by Wang (2015). The isolation plates were incubated at $30^{\circ} \mathrm{C}$ for 2 to 8 weeks or until bacterial growth was observed. All experiments were done in triplicate. Pure cultures obtained in the isolation media were grown and maintained in ISP 2 agar. 


\subsection{Phylogenetic analysis}

DNA was extracted from the endophytic bacteria following the procedures described by Araújo et al. (2002). Amplification of the 16S rRNA gene was done using the primer pair 27F-1492R (27F: 5'-CAGAGTTTGATCCTGGCT-3'; 1492R: 5'-AGGAGGTGATCCAGCCGCA-3') (Polz and Cavanaugh, 1998) procured from Sangon Biotech (Shanghai, China). The PCR mixture $(50 \mu \mathrm{L})$ contained $1 \mu \mathrm{L}$ DNA template, $0.5 \mathrm{U}$ Taq DNA polymerase, $5 \mu \mathrm{L} 10 \times$ buffer, $4 \mu \mathrm{L}$ dNTP Mix (100 $\mu \mathrm{M}$ each) and $0.5 \mu \mathrm{L}$ of each primer $(0.25 \mu \mathrm{M})$. Amplification of the $16 \mathrm{~S}$ rRNA genes was performed in a thermal cycler according to the following steps: $94^{\circ} \mathrm{C}$ initial denaturation for 10 min, followed by 32 cycles of denaturation at $94^{\circ} \mathrm{C}$ for $45 \mathrm{~s}$, annealing at $56^{\circ} \mathrm{C}$ for $30 \mathrm{~s}$ and extension at $72^{\circ} \mathrm{C}$ for $1 \mathrm{~min} 30 \mathrm{~s}$, and a final extension at $72^{\circ} \mathrm{C}$ for $10 \mathrm{~min}$. The amplified products were purified and sequenced by Sangon Biotech (Shanghai). The sequences obtained were identified using the EzTaxon database and the reference sequences of type species retrieved from the NCBI database. Multiple sequence alignments and genetic distance calculations were done using CLUSTAL_X program. A sequence similarity of less than $98.65 \%$ with the validly published type strains was considered to be a putative novel species (Kim et al., 2014). A neighbor-joining phylogenetic dendrogram based on the 16S rRNA gene sequences was then generated using the MEGA 5.1 software package (Tamura et al., 2011).

\subsection{Phosphate solubilization assay}

Inorganic phosphate solubilization assay was done using the method described by dos Santos Hara and de Oliveira (2004) and Wang (2015). Bacteria were grown in a modified phosphate-solubilizing medium (10 g/L glucose, $0.5 \mathrm{~g} / \mathrm{L}\left(\mathrm{NH}_{4}\right)_{2} \mathrm{SO}_{4}, 0.1 \mathrm{~g} / \mathrm{L} \mathrm{MgSO} \mathrm{MgH}_{4} \mathrm{O}, 0.5$ $\mathrm{g} / \mathrm{L}$ yeast extract, $0.2 \mathrm{~g} / \mathrm{L} \mathrm{KCl}, 0.2 \mathrm{~g} / \mathrm{L} \mathrm{NaCl}, 0.002 \mathrm{~g} / \mathrm{L} \mathrm{FeSO}_{4} \cdot 7 \mathrm{H}_{2} \mathrm{O}, 0.002 \mathrm{~g} / \mathrm{L} \mathrm{MnSO}_{4} \cdot 7 \mathrm{H}_{2} \mathrm{O}, 5.0$ $\mathrm{g} / \mathrm{L} \mathrm{Ca}_{3}\left(\mathrm{PO}_{4}\right)_{2}, 0.025 \mathrm{~g} / \mathrm{L}$ bromophenol blue, $20 \mathrm{~g} / \mathrm{L}$ agar, $\left.\mathrm{pH} 7.0\right)$. Development of a halo zone around the bacterial colony after $7-10$ days incubation at $28^{\circ} \mathrm{C}$ was considered as a positive result for phosphate solubilization. The diameters of the halo and colony were measured with a digital caliper and the phosphate solubilizing activity was described as phosphorus solubilizing index (PSI), and the equation can be delineated as PSI $=\mathrm{d}_{1}$ (halo) $/ \mathrm{d}_{2}$ (colony) (dos Santos Hara and de Oliveira, 2004). All experiments were done in triplicate. Solubilization was classified as low $(\mathrm{PSI}<2)$, moderate $(2 \leq \mathrm{PSI} \leq 3)$, or high $(\mathrm{PSI}>3)$.

\subsection{Nitrogen fixation assay}

For assessment of nitrogen fixation activity, bacteria were inoculated in both nitrogen-free culture (NFC) medium (10.0 g/L mannitol, $0.2 \mathrm{~g} / \mathrm{L} \mathrm{KH}_{2} \mathrm{PO}_{4}, 0.2 \mathrm{~g} / \mathrm{L} \mathrm{NaCl}, 0.2 \mathrm{~g} / \mathrm{L} \mathrm{MgSO}{ }_{4} \cdot 7 \mathrm{H}_{2} \mathrm{O}, 0.2 \mathrm{~g} / \mathrm{L}$ $\mathrm{CaSO}_{4} \cdot 2 \mathrm{H}_{2} \mathrm{O}, 5.0 \mathrm{~g} / \mathrm{L} \mathrm{CaCO}_{3}, 20.0 \mathrm{~g} / \mathrm{L}$ agar, $\mathrm{pH}$ 7.2) and Ashby medium $\left(0.2 \mathrm{~g} / \mathrm{L} \mathrm{KH}_{2} \mathrm{PO}_{4}, 0.2\right.$ $\mathrm{g} / \mathrm{L} \mathrm{MgSO}_{4}, 0.2 \mathrm{~g} / \mathrm{L} \mathrm{NaCl}, 5.0 \mathrm{~g} / \mathrm{L} \mathrm{CaCO}_{3}, 10.0 \mathrm{~g} / \mathrm{L}$ mannitol, $0.1 \mathrm{~g} / \mathrm{L} \mathrm{CaSO}_{4}, 15.0 \mathrm{~g} / \mathrm{L}$ agar, $\mathrm{pH}$ 7.0). Strains exhibiting growth on both of the media were likely to utilize nitrogen for its growth through fixation of atmospheric nitrogen (Sen and Sen, 1965).

\subsection{IAA synthesis}

For assessment of IAA synthesis, bacterial isolates were inoculated in tubes containing $8 \mathrm{~mL}$ of King's B medium (20 g/L peptone, $10 \mathrm{~g} / \mathrm{L}$ glycerol, $1.5 \mathrm{~g} / \mathrm{L} \mathrm{K}_{2} \mathrm{HPO}_{4}, 1.5 \mathrm{~g} / \mathrm{L} \mathrm{MgSO}$, pH 7.2) and kept in an incubated shaker $\left(120 \mathrm{rpm}, 5 \mathrm{~d}, 30^{\circ} \mathrm{C}\right)$. The tubes containing the culture broth were then centrifuged at 12,000 rpm for $5 \mathrm{~min}$. Equimolar concentration of Salkowski reagent $(1 \mathrm{~mL}$ $0.5 \mathrm{M} \mathrm{FeCl}_{3}$ dissolved in $50 \mathrm{~mL} 35 \% \mathrm{HClO}_{4}$ ) was added to $1.5 \mathrm{~mL}$ of supernatant. The mixture was incubated for $30 \mathrm{~min}$ and the absorbance was measured in a spectrophotometer at $530 \mathrm{~nm}$ (Giassi et al., 2016). Medium without bacterial suspension was used as a control. All experiments were done in triplicate.

\subsection{Siderophore production}

Chrome azurol S (CAS) agar medium (Alexander and Zuberer, 1991) was prepared to measure the bacterial siderophore production. Preparation of the CAS agar involved mixing of four separate sterilized solutions: Solution 1 (Fe-CAS indicator), Solution 2 
(piperazine-N,N'-bis(2-ethanesulphonic acid) or PIPES buffer solution), Solution 3 (Basal medium) and Solution 4 (10\%, w/v casamino acids). All the solutions were sterilized separately, cooled to $50^{\circ} \mathrm{C}$ and mixed with sufficient stirring to prevent formation of bubbles in the order as reported by Alexander and Zubere (1991). The bacterial isolates were inoculated on CAS agar and incubated at $28^{\circ} \mathrm{C}$ for 10 days. Formation of orange-color halo around the bacteria colony was considered as positive result for siderophore production.

\subsection{Antagonism assay}

The fungal causative agents of Verticillium wilt, i.e., Verticillium dahlia strain 991 and V. dahlia strain 7 were collected by Xinjiang Agricultural University, China, while Alternaria alternata (causative agent of leaf blight) was isolated by Xinjiang Institute of Ecology and Geography, Chinese Academy of Sciences, China. The three fungi were maintained on potato dextrose agar (PDA) at room temperature for antagonism assay. The pathogenicity of these fungi was verified through Koch's postulates (Byrd and Segre, 2016).

Antagonism against these fungal pathogens was assayed by dual-culture in-vitro method. Fungal disc (6 $\mathrm{mm}$ in diameter) containing 5-day old culture from PDA plates was placed at the center of a fresh PDA plate. Four bacterial cultures grown on ISP 2 agar were then streaked at the corner of the PDA plates, $3 \mathrm{~cm}$ away from the fungal disc. Plates without the bacterial isolates served as controls. All plates were incubated at $28^{\circ} \mathrm{C}$ until the fungal mycelia in control plates reached the edge of the plates. Colony growth inhibition (\%) was calculated by using the formula: $I=\left(R_{0}-R_{i}\right) / R_{0} \times 100 \%$, where $R_{0}$ is the radial growth of pathogen in control plates (measured in $\mathrm{mm}$ ), and $R_{i}$ is the radial growth of pathogen in test plates $(\mathrm{mm})$. All experiments were done in triplicate.

\section{Results}

\subsection{Diversity of endophytic bacteria}

No microbial growth was observed after 15 days of incubation at $30^{\circ} \mathrm{C}$ on ISP2 agar where the water used in the final rinse of surface-sterilization was plated. This indicated that the 3-step surface sterilization protocol was effective in inhibiting the growth of the epiphytic bacteria. The subsequent bacteria obtained during the isolation were, therefore, considered to be true endophytes.

\subsubsection{Composition of endophytic bacteria}

A total of 125 endophytes were isolated from surface sterilized tissues of F. sinkiangensis. Characterization by $16 \mathrm{~S}$ rRNA gene sequencing indicated that they belong to bacteria of 3 phyla, 13 orders, 23 classes, 29 genera, and 58 species. The phylum Actinobacteria accounted for 88 bacteria isolated from $F$. sinkiangensis. The remaining isolates were represented by the phyla Proteobacteria and Firmicutes (28 and 13 isolates, respectively) (Fig. 1). The most prevalent endophytic bacteria in F. sinkiangensis was the order Micrococcales, representing $33.6 \%$ of the total isolates. The most predominantly isolated classes among these isolates were Microbacteriaceae, Micrococcaceae and Nocardiaceae, representing 16.8\%, 12.8\% and 10.4\%, respectively (Fig. 2).

\subsubsection{Putative novel species}

Strain SX2RGS8 exhibited 95.2\% 16S rRNA gene sequence similarity with Porphyrobacter colymbi TPW-24 ${ }^{\mathrm{T}}$. While strain SX2R5S10 showed $97.6 \% 16 \mathrm{~S}$ rRNA gene sequence similarity with Paracoccus homiensis DD-R11 ${ }^{\mathrm{T}}$, strain SX2R71 exhibited 97.8\% 16S rRNA gene sequence similarity with Amycolatopsis magusensis KT2025 ${ }^{\mathrm{T}}$. Based on the consideration of Kim et al. (2014), it is likely that strains SX2RGS8, SX2R5S10 and SX2R71 are potential new members of the genera Porphyrobacter, Paracoccus and Amycolatopsis, respectively (Figs. 3-5).

\subsubsection{Tissue-specificity of endophytes}

The abundance of endophytic bacteria in root tissues was apparently higher than in stem. For instance, the distributions of the genera Bacillus, Kocuria, Nocardiopsis, Streptomyces, 
Sphingomonas and Williamsia were higher in roots than in stems, while the genus Microbacterium was more abundant in stems than in roots. Sixteen rare genera Actinophytocola, Agrococcus, Amycolatopsis, Bradyrhizobium, Curtobacterium, Devosia, Janibacter, Nocardioides, Methylobacterium, Mycobacterium, Paenibacillus, Paracoccus, Porphyrobacter, Promicromonospora, Pseudomonas and Ralstonia representing 20 isolates were isolated only in root tissue during the study. Thirteen genera Acinetobacter, Arthrobacter, Bacillus, Brevibacterium, Brevundimonas, Kocuria, Microbacterium, Micrococcus, Nocardiopsis, Pseudonocardia, Sphingomonas, Streptomyces and Williamsia were isolated from both the root and stem tissues. A total of 27 genera (representing 93.1\% of all genera obtained) occurred in roots, but only 13 genera (representing $44.8 \%$ of all genera) were isolated from stems (Fig. 6).

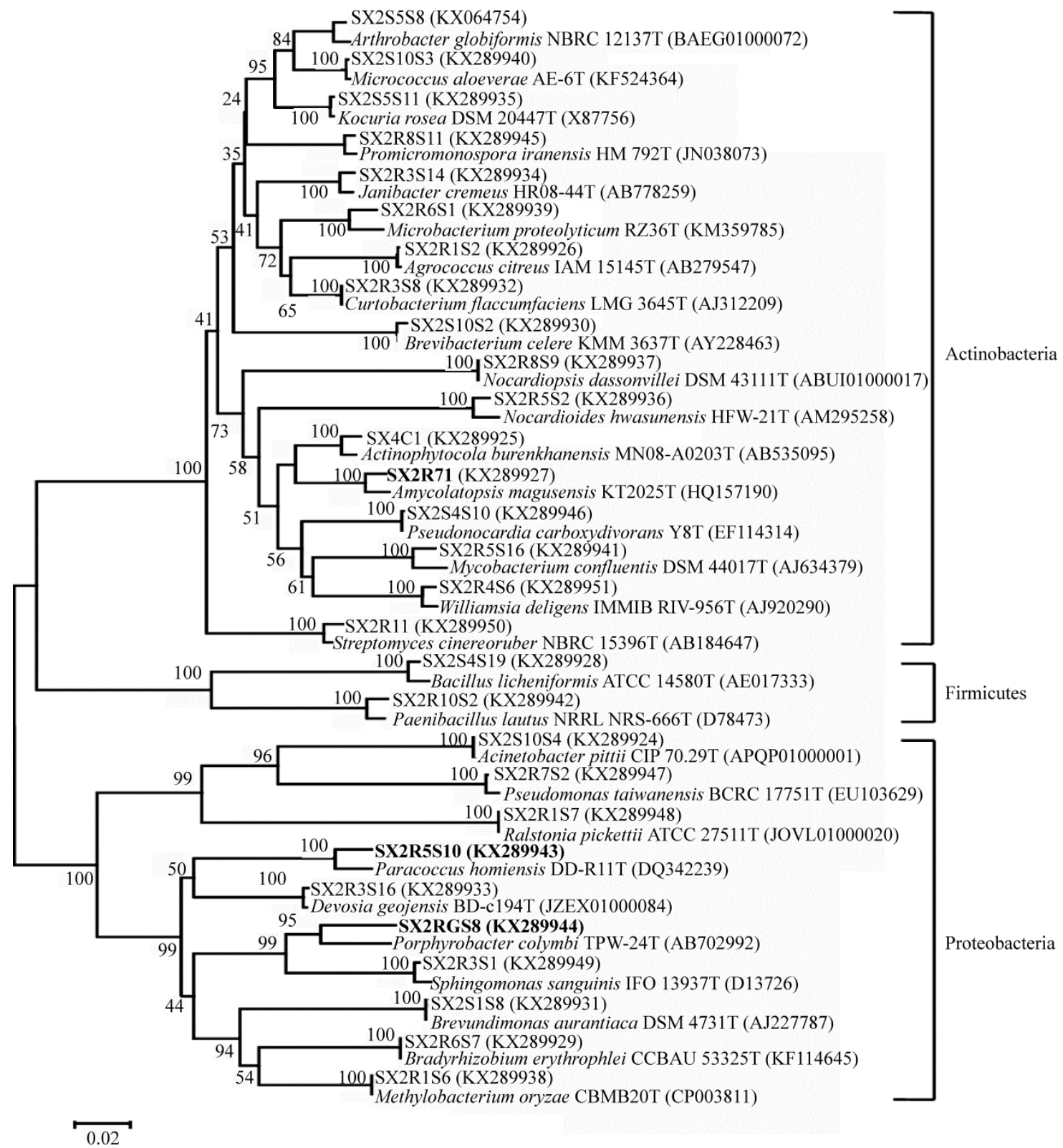

Fig. 1 Neighbor-joining phylogenetic dendrogram of representative endophytes from Ferula sinkiangensis indicating their relationship with the reference bacterial strains. Numbers in the branches represent the bootstrapping percentage that supports the branch with 1000 bootstrap resamplings. The scale bar represents 0.02 substitutions per nucleotide position. 
(a)

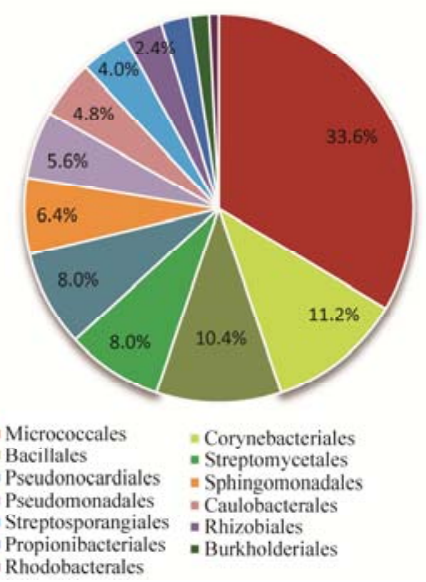

(b)
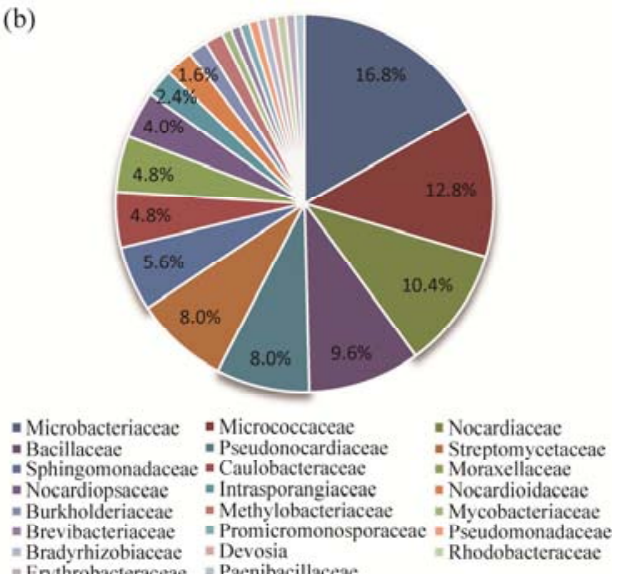

= Bradyrhizobiaceae $=$ Devosia

Erythrobacteraceae $=$ Paenibacillaceac

Fig. 2 Composition of 13 orders (a) and 23 classes (b) isolated from Ferula sinkiangensis
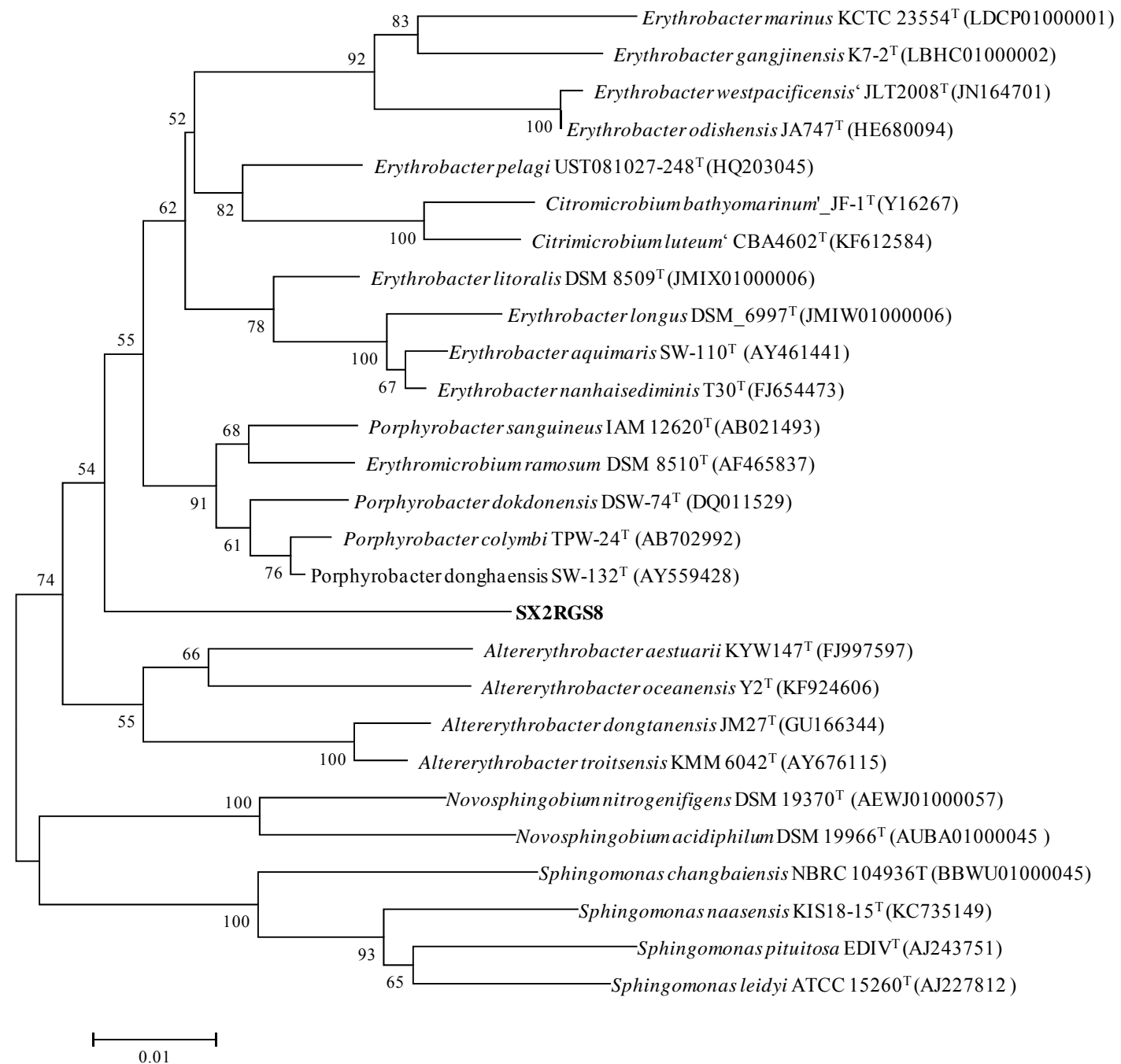

Fig. 3 Neighbor-joining phylogenetic tree of strain SX2RGS8 and its closely related type species based on the $16 \mathrm{~S}$ rRNA gene sequences. Bootstrap values (expressed as percentage of 1000 resamplings) of above $50 \%$ are shown at the branch points. The scale bar represents 0.01 substitutions per nucleotide position. 


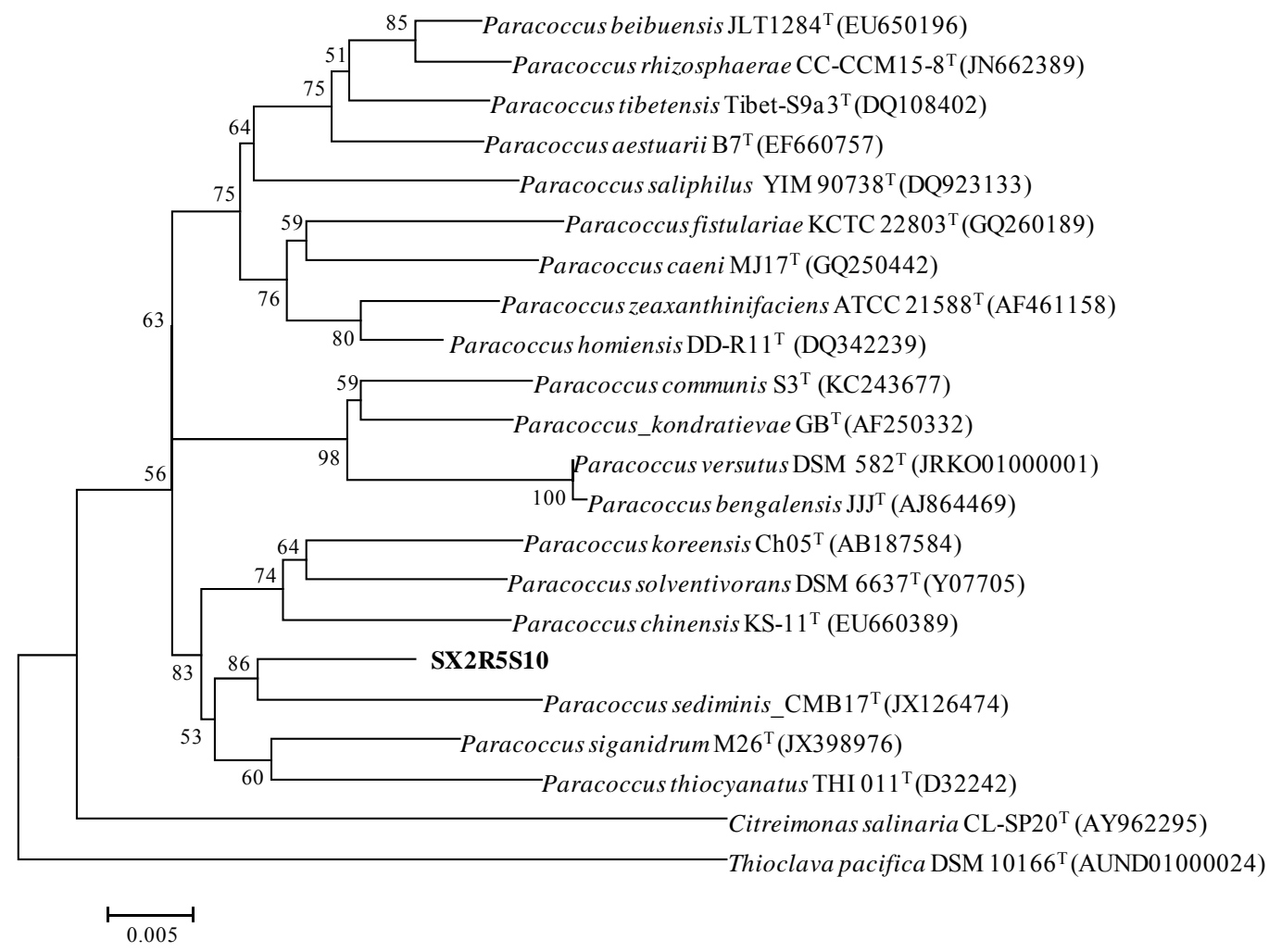

Fig. 4 Neighbor-joining phylogenetic tree based on 16S rRNA gene sequences showing the relationships between strain SX2R5S10 and related type species of the genus Paracoccus. Numbers at nodes are levels of bootstrap support (\%) for branch points (1000 resamplings). The scale bar represents 0.005 substitutions per nucleotide position.

\subsection{Growth promotion potential}

\subsubsection{Phosphate solubilization}

Of the total endophytic bacteria isolated, only $12.11 \%$ were observed to be positive for phosphate solubilization test (Fig. 7). Of these strains, 3.0\% showed strong, $4.5 \%$ moderate and $4.5 \%$ weak phosphate-solubilizing activities. These strains were restricted to the genera Acinetobacter, Microbacterium and Ralstonia (Table 1).

\subsubsection{Nitrogen fixation}

A large number of isolates (75.8\%) showed positive growth on both NFC and Ashby media. The results are indicative of the potential of these strains for nitrogen fixation. Percentage of $12.1 \%$ of these strains, mostly Microbacterium spp., was strongly positive for growth on nitrogen-free media. While $30.3 \%$ of the total strains showed moderately activity, $33.3 \%$ exhibited weakly positive for putative nitrogen fixing ability (Fig. 7). Other genera exhibiting growth on nitrogen-free media include Acinetobacter, Bacillus, and Williamsia (Table 1).

\subsubsection{IAA synthesis}

Importantly, $79.4 \%$ of the tested isolates were capable of producing IAA (Fig. 7). Among the different genera, Bacillus strains such as S4S19, R7S5, 3A6, 3A8 and R10S11 produced the highest amount of IAA (Table 1).

\subsubsection{Siderophore production}

A total of $57.1 \%$ of the total isolates were found to produce siderophore. The frequency of strains exhibiting strong activity was low (1.4\%; Fig. 7). Strains S4S19 (Bacillus), 3A6 (Bacillus), 
R10S11 (Bacillus) and S4S17 (Microbacterium) exhibited moderate siderophore production (Table 1).

\subsubsection{Antagonism assay}

A total of $40.6 \%$ of the total isolates exhibited antagonistic activity against A. alternata. The frequencies of bioactive strains inhibiting $V$. dahlia 991 and $V$. dahlia 7 were, however, $17.2 \%$ and $20.2 \%$, respectively. The strains 3A8 (Bacillus), S4S19 (Bacillus), R10S11 (Bacillus) and 3A6 (Bacillus) showed strong inhibitory action against all the three tested pathogenic fungi $A$. alternata, V. dahlia 991 and V. dahlia 7 (Table 1).

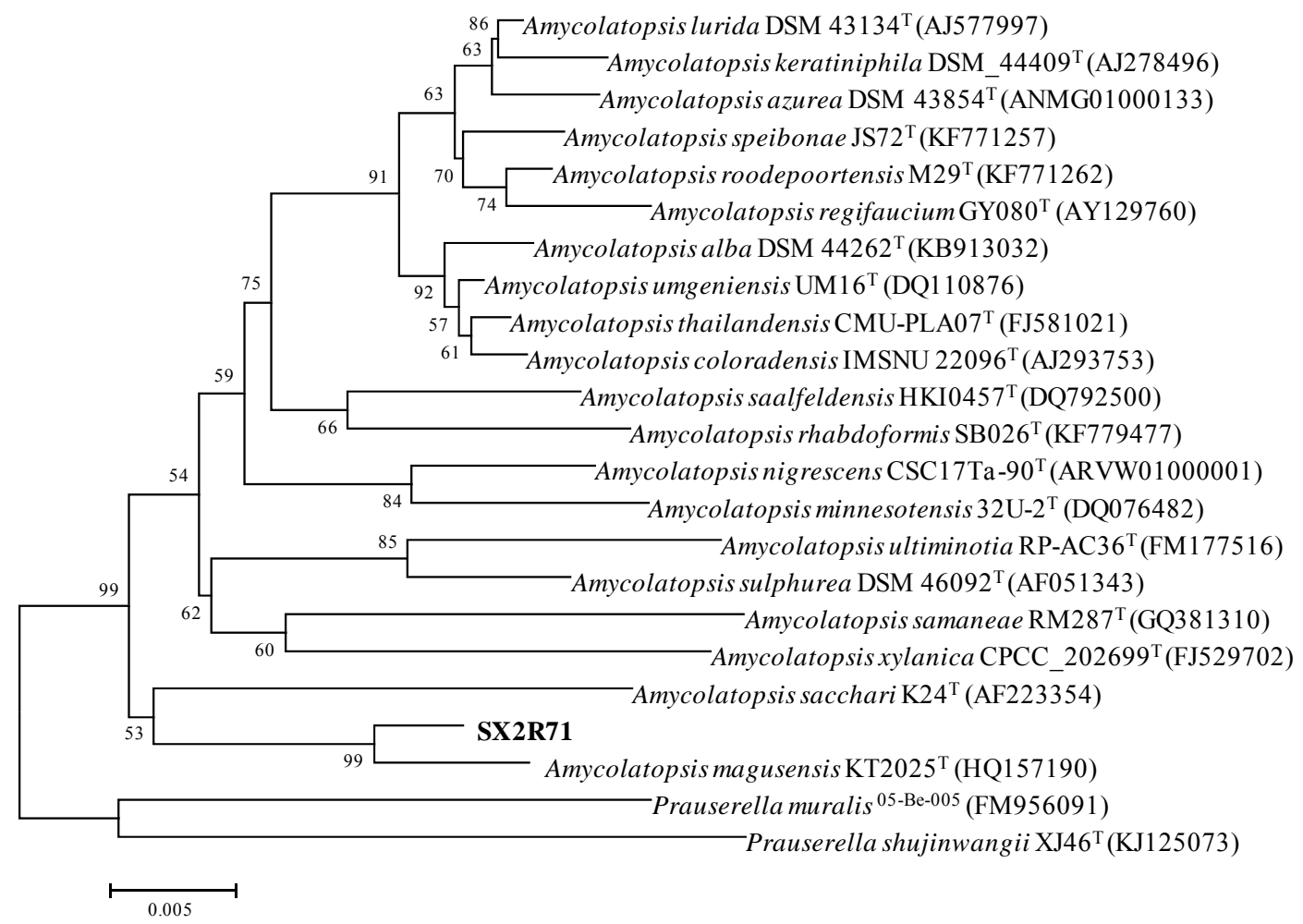

Fig. 5 Neighbor-joining phylogenetic tree based on 16S rRNA gene sequences of strain SX2R71 and its closely related species of the genus Amycolatopsis. Bootstrap values (expressed as percentages of 1000 resamplings) above $50 \%$ are shown at the nodes. Bar, 0.005 substitutions per nucleotide position.

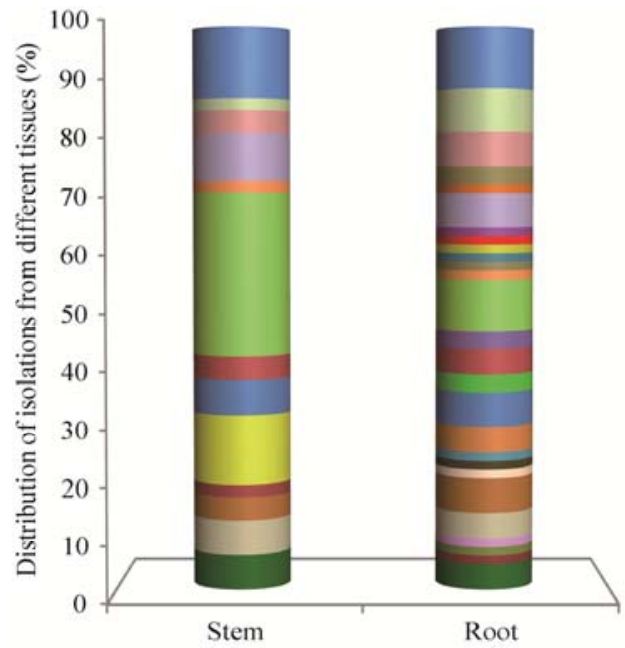

\begin{tabular}{|c|c|}
\hline -Williamsia & $\|$ Streptomyces \\
\hline -Sphingomonas & =Ralstonia \\
\hline = Pseudomonas & $=$ Pseudonocardia \\
\hline \multicolumn{2}{|c|}{ - Promicromonospora $=$ Porphyrobacter } \\
\hline =Paracoccus & -Paenibacillus \\
\hline = Mycobacterium & $=$ Micrococcus \\
\hline = Microbacterium & - Methylobacteriun \\
\hline$=$ Nocardiopsis & $=$ Nocardioides \\
\hline = Kocuria & $=$ Janibacter \\
\hline - Devosia & - Curtobacterium \\
\hline = Brevundimonas & - Brevibacterium \\
\hline -Bradyrhizobium & \#acillus \\
\hline Arthrobacter & $=$ Amycolatopsis \\
\hline Agrococcus & - Actinophytocola \\
\hline Acinetobacter & \\
\hline
\end{tabular}

Fig. 6 Distribution of endophytic strains in roots and stems of Ferula sinkiangensis 


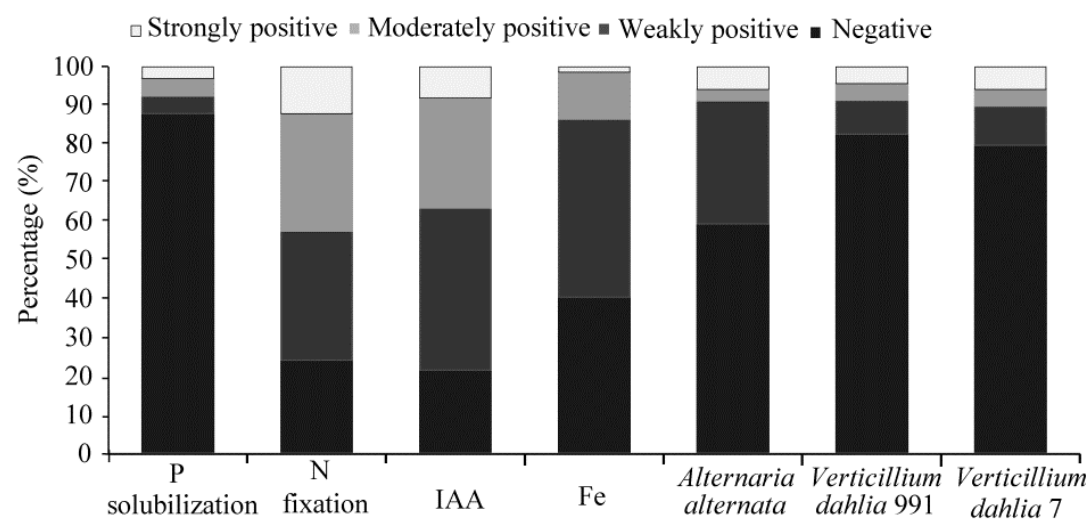

Fig. 7 Distribution of positive strains tested for growth promotion traits; IAA, indole-3-acetic acid.

Our results found that strains of R4S5 (Acinetobacter), 3A6 (Bacillus), 3A8 (Bacillus) and R10S11 (Bacillus) were positive for nitrogen fixation, IAA synthesis and siderophore production assays in addition to antagonistic activity against $A$. alternata and $V$. dahlia 7 . Few strains were positive for both PGP traits and biocontrol activity except for those four strains (Table 1). A representative picture illustrating the above activities is shown in Figure 8.

\section{Discussion}

Endophytes have been isolated and identified from various cereal crops as well as from medicinal plants (Liu et al., 2016). These microorganisms are known to play an important role in ecological adaptation of the host plant. They may act to facilitate plant fitness through production of phytohormones or to provide protection through production of biologically active metabolites (Bloemberg and Lugtenberg, 2001; Nimaichand et al., 2016). Unlike in other areas, plants in arid and desert areas often face prolonged abiotic stresses such as water limitation and salt accumulation. Such plants often tend to select bacteria endowed with growth promoting and stress resistance traits for its symbiotic association (Marasco et al., 2012; Soussi et al., 2016; Asaf et al., 2017). It is therefore necessary to understand the diverse population of endophytic bacteria associated with plants especially those in arid region to provide a greater insight into the plant-endophyte interactions, bioactivity, and its ecological role. This study was conducted with the aim to understand the distribution and bioactivity of endophytic bacteria from F. sinkiangensis found in arid land of Shihezi, Xinjiang. During the present study, a total of 125 isolates belonging to 3 phyla, 13 orders, 23 families, and 29 genera were isolated from surface-sterilized root and stem tissues of the plant. In a similar study conducted by our group on another Ferula plant samples collected from Hoboksar Mongol Autonomous County, Xinjiang (Liu et al., 2016), 170 endophytic bacteria distributed into 3 phyla, 15 orders, 20 families and 27 genera were isolated. Kaplan and co-workers isolated 31 endophytic strains belonging to 3 phyla, 20 genera from roots of two dominant shrubs found in Negev Desert (Kaplan et al., 2013). These results confirm the rich microbial diversity in plants grown in arid lands.

During the present study, root tissues were found to be a more suitable host for endophytic bacteria (52.8\% of all isolates) as compared with stem $(47.2 \%)$. This is further illustrated by the fact that a total of 27 genera were isolated from roots as compared with 13 genera from stems. Similar results were also found during endophytic studies in Azadirachia indica, Cucumis sativus, Ferula songorica, Maytenus austroyunnanensis and Oryza sativa (Mano and Morisaki, 2008; Verma et al., 2009; Qin et al., 2012; Liu et al., 2016). This phenomenon may be associated with the proposition that rhizospheric bacteria were laterally transferred towards the internal plant tissues (Santoyo et al., 2016). In addition, bacteria residing in the rhizosphere might also have the potential to colonize the plant roots, as living within plant tissues can provide an opportunity to be in contact with the plant's cells and thereby exert a direct beneficial effect. 
Table 1 Characteristics and growth promotion screening of some representative strains

\begin{tabular}{|c|c|c|c|c|c|c|c|c|c|}
\hline \multirow[b]{2}{*}{ Strain } & \multirow{2}{*}{$\begin{array}{c}\text { Generic } \\
\text { affiliation (16S } \\
\text { rRNA gene } \\
\text { homology) }\end{array}$} & \multirow[b]{2}{*}{ Tissue } & \multicolumn{4}{|c|}{ Growth-promoting activities } & \multicolumn{3}{|c|}{ Biocontrol potential } \\
\hline & & & $\begin{array}{l}\text { Phosphate } \\
\text { solubilization }\end{array}$ & $\begin{array}{c}\text { Nitrogen } \\
\text { fixation }\end{array}$ & IAA & $\begin{array}{l}\text { Siderophore } \\
\text { production }\end{array}$ & $\begin{array}{c}\text { Alternaria } \\
\text { alternata }\end{array}$ & $\begin{array}{l}\text { Verticillium } \\
\text { dahlia } 991\end{array}$ & $\begin{array}{c}\text { Verticillium } \\
\text { dahlia } 7\end{array}$ \\
\hline S5S6 & Acinetobacter sp. & Stem & ++ & ++ & + & - & + & - & - \\
\hline S10S4 & Acinetobacter sp. & Stem & +++ & + & + & - & + & - & ++ \\
\hline R4S5 & Acinetobacter sp. & Root & +++ & + & + & + & + & - & + \\
\hline R4S7 & Acinetobacter sp. & Root & ++ & + & + & + & + & - & - \\
\hline $3 \mathrm{~A} 6$ & Bacillus sp. & Root & - & + & +++ & ++ & ++ & +++ & ++ \\
\hline $3 \mathrm{~A} 8$ & Bacillus sp. & Root & - & ++ & +++ & + & +++ & +++ & +++ \\
\hline 4B5 & Bacillus sp. & Root & - & - & ++ & - & + & + & + \\
\hline S3S4 & Bacillus sp. & Stem & - & - & ++ & + & + & - & - \\
\hline S4S19 & Bacillus sp. & Stem & - & - & +++ & ++ & +++ & +++ & +++ \\
\hline S5S2 & Bacillus sp. & Stem & - & + & ++ & - & - & - & - \\
\hline R5S1 & Bacillus sp. & Root & - & + & ++ & + & + & - & - \\
\hline R10S11 & Bacillus sp. & Root & - & + & +++ & +++ & +++ & ++ & +++ \\
\hline S1S8 & Brevibacterium sp. & Stem & - & - & + & ++ & + & ++ & - \\
\hline $\mathrm{S} 10 \mathrm{~S} 2$ & Brevibacterium sp. & Stem & - & + & ++ & ++ & - & - & + \\
\hline S3S6 & Brevibacterium sp. & Stem & - & + & + & + & - & + & - \\
\hline S3S7 & Brevibacterium sp. & Stem & - & - & + & + & + & - & - \\
\hline R4S4 & Janibacter sp. & Root & - & + & ++ & + & - & - & - \\
\hline S3S2 & Kocuria sp. & Stem & - & + & I & 1 & + & - & - \\
\hline S5S11 & Kocuria sp. & Stem & - & + & ++ & - & + & - & +++ \\
\hline $\mathrm{R} 7 \mathrm{~S} 1$ & Kocuria sp. & Root & - & +++ & ++ & - & - & - & - \\
\hline S3S1 & Microbacterium sp. & Stem & - & ++ & + & + & +++ & - & - \\
\hline S3S9 & Microbacterium sp. & Stem & + & ++ & + & - & + & - & - \\
\hline S3S10 & Microbacterium sp. & Stem & - & ++ & ++ & + & + & - & - \\
\hline S3S12 & Microbacterium sp. & Stem & - & ++ & + & - & - & + & + \\
\hline $\mathrm{S} 4 \mathrm{~S} 13$ & Microbacterium sp. & Stem & - & - & ++ & + & + & - & - \\
\hline S4S17 & Microbacterium sp. & Stem & - & +++ & + & ++ & + & - & - \\
\hline S5S4 & Microbacterium sp. & Stem & - & - & ++ & + & + & - & - \\
\hline S6S5 & Microbacterium sp. & Stem & - & + & ++ & + & - & ++ & - \\
\hline S6S8 & Microbacterium sp. & Stem & - & +++ & - & + & - & - & - \\
\hline R3S6 & Microbacterium sp. & Root & - & + & + & + & - & + & + \\
\hline R6S4 & Microbacterium sp. & Root & - & +++ & + & + & - & + & - \\
\hline S10S3 & Micrococcus sp. & Stem & - & + & + & - & - & - & ++ \\
\hline RGS8 & Porphyrobacter sp. & Root & l & / & ++ & - & + & - & - \\
\hline R1S10 & Ralstonia sp. & Root & ++ & - & + & + & - & - & - \\
\hline S4S2 & Sphingomonas sp. & Stem & - & + & I & / & + & - & - \\
\hline S7S1 & Sphingomonas sp. & Stem & - & ++ & + & + & 1 & I & 1 \\
\hline S1S2 & Williamsia sp. & Stem & - & + & - & + & - & - & - \\
\hline S4S1 & Williamsia sp. & Stem & - & + & - & + & - & - & - \\
\hline S6S10 & Williamsia sp. & Stem & - & ++ & - & ++ & - & - & + \\
\hline $\mathrm{R} 3 \mathrm{~S} 10$ & Williamsia sp. & Root & - & ++ & - & - & ++ & - & - \\
\hline $\mathrm{R} 3 \mathrm{~S} 13$ & Williamsia sp. & Root & - & ++ & ++ & - & - & + & - \\
\hline R6S11 & Williamsia sp. & Root & - & ++ & - & + & - & - & - \\
\hline
\end{tabular}



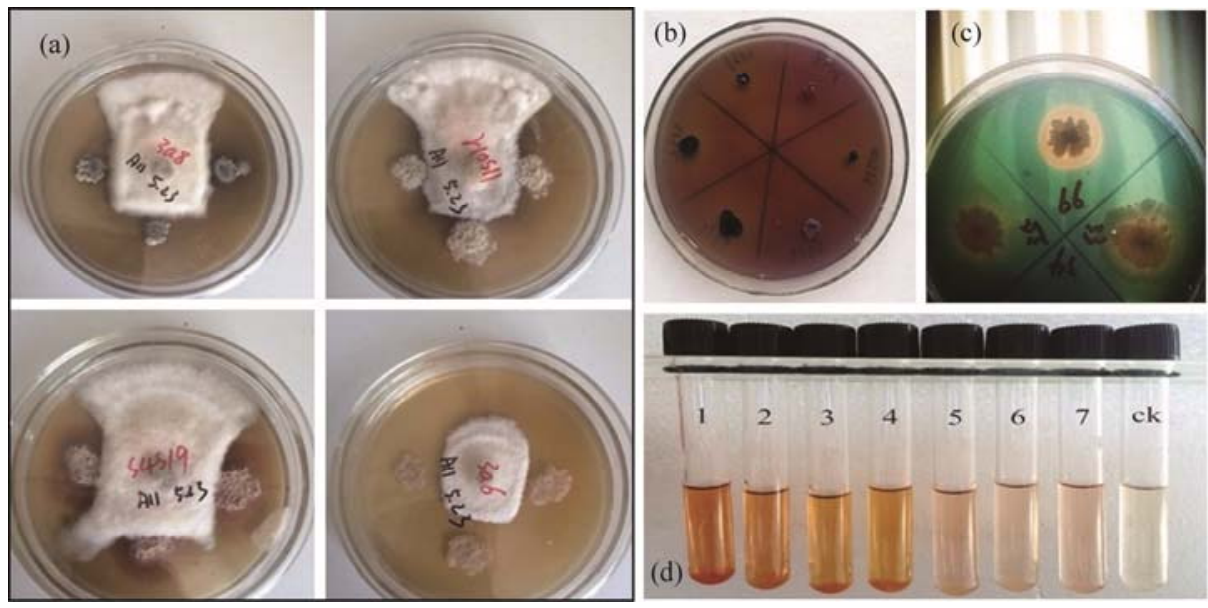

Fig. 8 Representation of plant growth promoting traits by the endophytic bacteria isolated from Ferula sinkiangensis. (a) biocontrol activity against Alternaria alternata; (b) phosphate solubilization assay; (c) siderophore production assay; and (d) IAA biosynthesis assay (1, S4S19-Bacillus; 2, 3A8-Bacillus; 3, R10S11-Bacillus; 4, 3A6-Bacillus; 5, S4S13-Microbacterium; 6, S4S3-Microbacterium; 7, S6S7-Microbacterium; ck, control).

Microbial assemblages and their species distributions in specific environment are determined by the environmental parameters (Jose and Jebakumar, 2014; Sibanda et al., 2017). Microorganisms isolated from unusual environments such as endophytes of arid plants were most likely unique in nature. In a recent study, two novel bacteria of higher bacterial hierarchy (of the status novel order) were isolated from arid soils in Xinjiang (Zhang et al., 2016a, b). Bacillus shacheensis strain HNA-14 ${ }^{\mathrm{T}}$, a moderately halophilic bacterium, was isolated from a soil sample in Shache County, Xinjiang (Lei et al., 2014). And another novel halophilic bacterium Okibacterium endophyticum was isolated from roots of halophyte Salsola affinis collected from Xinjiang (Wang et al., 2015). The rich endophytic resources of arid regions in Xinjiang are further proved by the isolation of putative novel taxa in the current study. Based on the 16S rRNA gene sequences analysis, strains SX2RGS8, SX2R5S10 and SX2R71 isolated from root tissues of F. sinkiangensis could be new member of the genera Porphyrobacter, Paracoccus, and Amycolatopsis, respectively.

The plant growth-promoting activities of microorganisms can be observed by direct and indirect methods. Direct plant growth promotion requires production or supplementation of essential factors required for the growth of the plant through biological nitrogen fixation, solubilization of phosphates, siderophore production, and IAA synthesis. Among these factors, biological nitrogen fixation and solubilization of phosphates are important as these processes can convert the most readily but unutilizable nitrogen and phosphorus sources to accessible forms (Meunchang et al., 2006; Nimaichand et al., 2016). Nitrogen fixation by bacteria can be accessed directly by their ability to grow on nitrogen-free media or reduce acetylene, and indirectly through PCR amplification of nif genes (Gtari et al., 2012). In the current study, a large number of the endophytes $(75.8 \%)$ were able to grow in nitrogen-free medium, which gives an indirect hint on its ability to fix nitrogen. However, additional experiment such as detection of nifH genes will be necessary to further confirm its capacity to fix nitrogen. Additionally, seven strains belonging to Microbacterium and Acinetobacter were positive for growth in nitrogen-free medium (nitrogen fixation) and phosphate solubilization activity.

Endophytes also play an important role in growth promotion by controlling and minimizing the deleterious effects of external factors such as fungal infections, water stress, etc. This, in turn, improves the overall health and fitness of the plant. One such example is the IAA synthesis by endophytes that promotes the growth of plant and, thereby, increases the yield (Patten and Glick, 1996; Aldesuquy et al., 1998; Pereira et al., 2012). Several reports indicated that the production of siderophores by beneficial microbes is perceived as a means of biological control of 
phytopathogens especially effective in controlling fungal pathogens (Schippers et al., 1987). Additionally, microbes depicting different modes of action have a higher success rate in suppressing disease, and such microbes are potential good candidates as biocontrol agent (Palaniyandi et al., 2013). In this study, $79.4 \%$ and $57.1 \%$ of the total isolates were capable of producing IAA and siderophore, respectively. And, $40.6 \%$ of the strains inhibit the growth of $A$. alternata, $17.2 \%$ and $20.2 \%$ strains were positive for antagonism against $V$. dahlia 991 and $V$. dahlia 7, respectively. Among these positive strains, four strains showed strong antagonistic activities against all the three pathogenic fungi. Similar results were also reported in halophytes from Xinjiang (Wang, 2015), Allium sativum from Shanxi (Cui et al., 2008), and citrus rootstocks from Brazil (Giassi et al., 2016).

\section{Conclusions}

The present study represents the first report on the study of distribution and bioactivity of endophytic bacteria from $F$. sinkiangensis. The study showed that the approach involving microbial cultivation along with $16 \mathrm{~S}$ rRNA gene sequences analysis is a useful tool in exploring endophytic bacterial resources on different tissues. These results also provide a preliminary framework for exploring endophytic bacteria associated with endangered medicinal plant $F$. sinkiangensis as potential bioinoculants for agriculture application. In the light of this, our future work will be directed towards exploring more endophytic bacteria resources from arid and semi-arid environment and towards understanding the mechanisms of biocontrol and plant growth promotion with special emphasis on nitrogen fixation, phosphate solubilization, IAA synthesis, siderophore production and resistance to different pathogenic fungi.

\section{Acknowledgements}

This work was supported by the National Natural Science Foundation of China (U1403101, 31200008), the China Postdoctoral Science Foundation (2016M602566), the Visiting Scholar Grant of State Key Laboratory of Biocontrol, Sun Yat-Sen University (SKLBC14F02) and the West Light Foundation of the Chinese Academy of Sciences. The author LI Wenjun was also supported by Hundred Talents Program of the Chinese Academy of Sciences and Guangdong Province Higher Vocational Colleges \& Schools Pearl River Scholar Funded Scheme (2014).

\section{References}

Aldesuquy H S, Mansour F A, Abo-Hamed S A. 1998. Effect of the culture filtrates of Streptomyces on growth and productivity of wheat plants. Folia Microbiologica, 43(5): 465-470.

Alexander D B, Zuberer D A. 1991. Use of chrome azurol S reagents to evaluate siderophore production by rhizosphere bacteria. Biology and Fertility of Soils, 12(1): 39-45.

Araújo W L, Marcon J, Maccheroni W Jr, et al. 2002. Diversity of endophytic bacterial populations and their interaction with Xylella fastidiosa in citrus plants. Applied and Environmental Microbiology, 68(10): 4906-4914.

Asaf S, Khan M A, Khan A L, et al. 2017. Bacterial endophytes from arid land plants regulate endogenous hormone content and promote growth in crop plants: an example of Sphingomonas sp. and Serratia marcescens. Journal of Plant Interactions, 12(1): $31-38$.

Bloemberg G V, Lugtenberg B J J. 2001. Molecular basis of plant growth promotion and biocontrol by rhizobacteria. Current Opinion in Plant Biology, 4(4): 343-350.

Boukhalfa H, Crumbliss A L. 2002. Chemical aspects of siderophore mediated iron transport. Biometals, 15(4): 325-339.

Byrd A L, Segre J A. 2016. Adapting Koch's postulates. Science, 351(6270): 224-226.

Cui B M, Pan Q N, Zhang P P, et al. 2008. Isolation and identification of endogenetic bacteria and screening of their antagonistic bacteria in garlic. Acta Botanica Boreali-Occidentalia Sinica, 28(11): 2343-2348. (in Chinese)

dos Santos Hara F A, de Oliveira L A. 2004. Physiological and ecological characteristics of rhizobio isolated deriving of acid and alic soils of Presidente Figueiredo, Amazonas State. Acta Amazonica, 34(3): 343-357. (in Portuguese)

Emmert E A B, Handelsman J. 1999. Biocontrol of plant disease: a (Gram-) positive perspective. FEMS Microbiology Letters, 171(1): $1-9$ 
Feng Y, Shen D, Song W. 2006. Rice endophyte Pantoea agglomerans YS19 promotes host plant growth and affects allocations of host photosynthates. Journal of Applied Microbiology, 100(5): 938-945.

Giassi V, Kiritani C, Kupper K C. 2016. Bacteria as growth-promoting agents for citrus rootstocks. Microbiological Research, 190: 46-54.

Gtari M, Ghodhbane-Gtari F, Nouioui I, et al. 2012. Phylogenetic perspectives of nitrogen-fixing actinobacteria. Archives of Microbiology, 194(1): 3-11.

Hallmann J, Quadt-Hallmann A, Rodríguez-Kábana R, et al. 1998. Interactions between Meloidogyne incognita and endophytic bacteria in cotton and cucumber. Soil Biology and Biochemistry, 30(7): 925-937.

He S T, Zhi X Y, Jiang H C, et al. 2015. Biogeography of Nocardiopsis strains from hypersaline environments of Yunnan and Xinjiang Provinces, western China. Scientific Reports, 5: 13323.

Jose P A, Jebakumar S R D. 2014. Unexplored hypersaline habitats are sources of novel actinomycetes. Frontiers in Microbiology, 5: 242, doi: 10.3389/fmicb.2014.00242.

Kaplan D, Maymon M, Agapakis C M, et al. 2013. A survey of the microbial community in the rhizosphere of two dominant shrubs of the Negev Desert highlands, Zygophyllum dumosum (Zygophyllaceae) and Atriplex halimus (Amaranthaceae), using cultivation-dependent and cultivation-independent methods. American Journal of Botany, 100(9): 1713-1725.

Kim M, Oh H S, Park S C, et al. 2014. Towards a taxonomic coherence between average nucleotide identity and 16S rRNA gene sequence similarity for species demarcation of prokaryotes. International Journal of Systematic and Evolutionary Microbiology, 64(2): 346-351.

Lei Z C, Qiu P, Ye R Y, et al. 2014. Bacillus shacheensis sp. nov., a moderately halophilic bacterium isolated from a saline-alkali soil. The Journal of General and Applied Microbiology, 60(3): 101-105.

Liu Y H, Guo J W, Salam N, et al. 2016. Culturable endophytic bacteria associated with medicinal plant Ferula songorica: molecular phylogeny, distribution and screening for industrially important traits. 3 Biotech, 6(2): 209.

Lodewyck C, Vangronsveld J, Porteous F, et al. 2002. Endophytic bacteria and their potential applications. Critical Reviews in Plant Sciences, 21(6): 583-606.

Mano H, Morisaki H. 2008. Endophytic bacteria in the rice plant. Microbes and Environments, 23(2): 109-117.

Marasco R, Rolli E, Ettoumi B, et al. 2012. A drought resistance-promoting microbiome is selected by root system under desert farming. PLoS ONE, 7(10): e48479.

Meunchang S, Panichsakpatana S, Weaver R W. 2006. Tomato growth in soil amended with sugar mill by-products compost. Plant and Soil, 280(1-2): 171-176.

Nimaichand S, Devi A M, Li W J. 2016. Direct plant growth-promoting ability of actinobacteria in grain legumes. In: Subramaniam G, Arumugam S, Rajendran V. Plant Growth Promoting Actinobacteria: A New Avenue for Enhancing the Productivity and Soil Fertility of Grain Legumes. Singapore: Springer, 1-16.

Palaniyandi S A, Yang S H, Zhang L X, et al. 2013. Effects of actinobacteria on plant disease suppression and growth promotion. Applied Microbiology and Biotechnology, 97(22): 9621-9636.

Patten C L, Glick B R. 1996. Bacterial biosynthesis of indole-3-acetic acid. Canadian Journal of Microbiology, 42(3): 207-220.

Pereira G V, Magalhães K T, Lorenzetii E R, et al. 2012. A multiphasic approach for the identification of endophytic bacterial in strawberry fruit and their potential for plant growth promotion. Microbial Ecology, 63(2): 405-417.

Pimenov M G, Leonov M V. 2004. The Asian Umbelliferae biodiversity database (ASIUM) with particular reference to South-West Asian taxa. Turkish Journal of Botany, 28(1-2): 139-145.

Polz M F, Cavanaugh C M. 1998. Bias in template-to-product ratios in multitemplate PCR. Applied and Environmental Microbiology, 64(10): 3724-3730.

Qin S, Li J, Chen H H, et al. 2009. Isolation, diversity, and antimicrobial activity of rare actinobacteria from medicinal plants of tropical rain forests in Xishuangbanna, China. Applied and Environmental Microbiology, 75(19): 6176-6186.

Qin S, Chen H H, Zhao G Z, et al. 2012. Abundant and diverse endophytic actinobacteria associated with medicinal plant Maytenus austroyunnanensis in Xishuangbanna tropical rainforest revealed by culture-dependent and culture-independent methods. Environmental Microbiology Reports, 4(5): 522-531.

Santoyo G, Moreno-Hagelsieb G, del Carmen Orozco-Mosqueda M, et al. 2016. Plant growth-promoting bacterial endophytes. Microbiological Research, 183: 92-99.

Schippers B, Bakker A W, Bakker P A H M. 1987. Interactions of deleterious and beneficial rhizosphere microorganisms and the effect of cropping practices. Annual Review of Phytopathology, 25(1): 339-358.

Sen M, Sen S P. 1965. Interspecific transformation in Azotobacter. Microbiology, 41(1): 1-6.

Sibanda T, Selvarajan R, Tekere M. 2017. Synthetic extreme environments: overlooked sources of potential biotechnologically relevant microorganisms. Microbial Biotechnology, doi: 10.1111/1751-7915.12602. (in Press) 
Soussi A, Ferjani R, Marasco R, et al. 2016. Plant-associated microbiomes in arid lands: diversity, ecology and biotechnological potential. Plant and Soil, 405(1-2): 357-370.

Tamura K, Peterson D, Peterson N, et al. 2011. MEGA5: molecular evolutionary genetics analysis using maximum likelihood, evolutionary distance, and maximum parsimony methods. Molecular Biology and Evolution, 28(10): 2731-2739.

Triplett E W. 1996. Diazotrophic endophytes: progress and prospects for nitrogen fixation in monocots. Plant and Soil, 186(1): 29-38.

Verma V C, Gond S K, Kumar A, et al. 2009. Endophytic actinomycetes from Azadirachta indica A. Juss.: Isolation, diversity, and anti-microbial activity. Microbial Ecology, 57(4): 749-756.

Vurukonda S S K P, Vardharajula S, Shrivastava M, et al. 2016. Enhancement of drought stress tolerance in crops by plant growth promoting rhizobacteria. Microbiological Research, 184: 13-24.

Wang H F. 2015. Study on biodiversity of endophytic bacteria isolated from four Chenopodiaceae halophytes in Xinjiang and evaluation of their growth-promoting function and salt-tolerance ability. PhD Dissertation. Urumqi: Xinjiang Institute of Ecology and Geography, Chinese Academy of Sciences. (in Chinese)

Wang H F, Zhang Y G, Li L, et al. 2015. Okibacterium endophyticum sp. nov., a novel endophytic actinobacterium isolated from roots of Salsola affinis C. A. Mey. Antonie van Leeuwenhoek, 107(3): 835-843.

Wang W F, Zhai Y Y, Cao L X, et al. 2016. Illumina-based analysis of core actinobacteriome in roots, stems, and grains of rice. Microbiological Research, 190: 12-18.

Wang X R, Wang Y X, Tian J, et al. 2009. Overexpressing AtPAP15 enhances phosphorus efficiency in soybean. Plant Physiology, 151(1): 233-240.

Weller D M. 1988. Biological control of soilborne plant pathogens in the rhizosphere with bacteria. Annual Review of Phytopathology, 26(1): 379-407.

Zhang Y G, Chen J Y, Wang H F, et al. 2016a. Egicoccus halophilus gen. nov., sp. nov., a halophilic, alkalitolerant actinobacterium and proposal of Egicoccaceae fam. nov. and Egicoccales ord. nov. International Journal of Systematic and Evolutionary Microbiology, 66(2): 530-535.

Zhang Y G, Wang H F, Yang L L, et al. 2016b. Egibacter rhizosphaerae gen. nov., sp. nov., an obligately halophilic, facultatively alkaliphilic actinobacterium and proposal of Egibaceraceae fam. nov. and Egibacterales ord. nov. International Journal of Systematic and Evolutionary Microbiology, 66(1): 283-289. 